\title{
System Dynamics Approach in LCA for PET-Renewable Raw Materials Impact
}

\author{
Pablo Aarón Anistro Jiménez, Carlos E. Escobar Toledo \\ Department of Chemical Engineering, National University of Mexico (UNAM), Mexico City, Mexico \\ Email: carloset@unam.mx
}

Received 21 June 2015; accepted 14 July 2015; published 17 July 2015

Copyright (C) 2015 by authors and Scientific Research Publishing Inc.

This work is licensed under the Creative Commons Attribution International License (CC BY). http://creativecommons.org/licenses/by/4.0/

(c) (i) Open Access

\begin{abstract}
It has been shown that system dynamics and life-cycle analysis together provide an analytical tool to study different impacts between variables in decision-making process. This paper presents an application of this approach toward to a plastic material of quotidian use, considering both, a production chain using renewable resources and petrochemical production of Polyethylene Terephthalate, used as a beverage bottle application, and showing its impacts to the system when production replacement of non-renewable resources is allowed. We have already studied the substitution between different materials: glass and aluminum.
\end{abstract}

\section{Keywords}

System Dynamics, Life Cycle Analysis (LCA), Dynamical Modeling, Polyethylene Terephthalate (PET)

\section{Introduction}

The life cycle analysis (LCA) of a plastic resin, can respond to complex behaviors of market interventions and technological change, as well as, to social requirements expressed during governmental policies formulation.

System dynamics is a discipline that provides distinctive concepts and tools to allow the study of accumulation and feedback effects in complex systems. These effects can make a system to behave in complicated forms very different from the expected behavior compared with static or linear models [1]. The system dynamics models focus on the structure and behavior of systems composed of interacting feedback loops. System dynamics models are different from other optimization and equilibrium models as it focuses on the disequilibrium dynamics and complexities, through decision rules, stocks and flows.

The strength of system dynamics consists in its ability to examine how the system structure influences decisions and how systems react to these decisions over time. 
As said early, systems dynamics models allow exploration of futures and justify the development of possible scenarios.

In the present study, the relevant technological routes are: 1) PET production from renewable resources and its counterpart, production from oil and gas, non-renewable resources, and, 2) recovered and recycled material coming from the packaging industry.

System dynamics models are particularly useful in LCA studies, in order to estimate the environmental impacts of future changes in existing products [2]-[4]. They are also support to the probability of success estimation to product changes and assist in identifying the uncertainty sources in order to find robust solutions. Essentially, system dynamics brings temporality features and feedback to quantitative indicators from LCA.

\section{Plastics Dynamics}

Man-made polymers, obtained from natural sources, were displaced by those of petrochemical origin considering the petrochemical industry growth, mainly in the 1930's. It is from the 1980's and particularly the 1990's, biopolymers, and natural fibers, have increased their participation and significance in a growing variety of applications. Raw materials coming from biological processes are employed in the production of biodegradable materials, as well as non-biodegradable materials. Bio-materials superiority in terms of environmental impact has been the main driving force that has generated this increase, and it is expecting to be maintained in the future.

Reviews to different LCA studies applied to polymers obtained from biological and petrochemical resources, [5]; Patel [6], reveals questionable assumptions and uncertainties, as for example, the framework used to perform LCA, in which the commonly used approach is known as cradle to factory gate. This excludes relevant stages of materials flows to get to its final disposal. Those stages include the consideration of various options for waste treatment and recycling, due to high impact in final result.

Between the relevant results of LCA studies reviewed by Patel to different materials, materials produced from biological sources, clearly contribute to energy saving and greenhouse gases (GHG) reduction; however, at the same time it is clear that performance of these materials will not exceed its synthetic counterpart.

On the other hand, Pilz [7] has considered some of the weaknesses identified in previous studies, highlighting the approach, now from the cradle to the grave, to quantify plastics products impacts throughout the full life cycle; the study does not intent to set a premise of superiority of the plastics over other materials, since , all materials have characteristics that make them well suited to a greater or lesser extent of applications, in many cases, solution to a specific application , in terms of efficiency, is a combination of different materials.

In this approach, material selection will depend on factors such as the deposition impact or a suitable waste recovery system. In these cases, the solution is dependent on the country and is attached to the number or proportion of applications for the material. However this study does not address plastics from renewable sources because today market low impact recognizes the future role of the materials from renewable sources on plastics industry.

The study makes distinction of two production categories for renewable sources plastics. First, the monomer production to polymer manufacture, where the commercial challenge is competing against high-volume production, in terms of production economics and processing equipment adaptation. Second, monomer high volume production from renewable sources, provide raw material to polymerization plants. In both cases, chemical mechanisms are tested and presented important developments at an increasing rate of growth [8]. In the present work is considered this second category which presents an important technological development.

\section{Methods}

The present study is constituted as a contribution to the methodology developed by Escobar [9], in order to incorporate system dynamics approach [10], to the analysis of plastic products systems Figure 1, prior to exergetic and multicriteria analysis proposed by Mejia [11]. Major interest has been developed in plastics life cycleanalysis and research, to minimize their deposition and therefore its environmental impact. The proposed model is focused to bottle PET resin behavior.

Using multicriteria decision making we have also studied the possibility of substitution between glass and aluminum. The criteria used in this case are the following:

1) Total irreversibility (MJ/fu). 


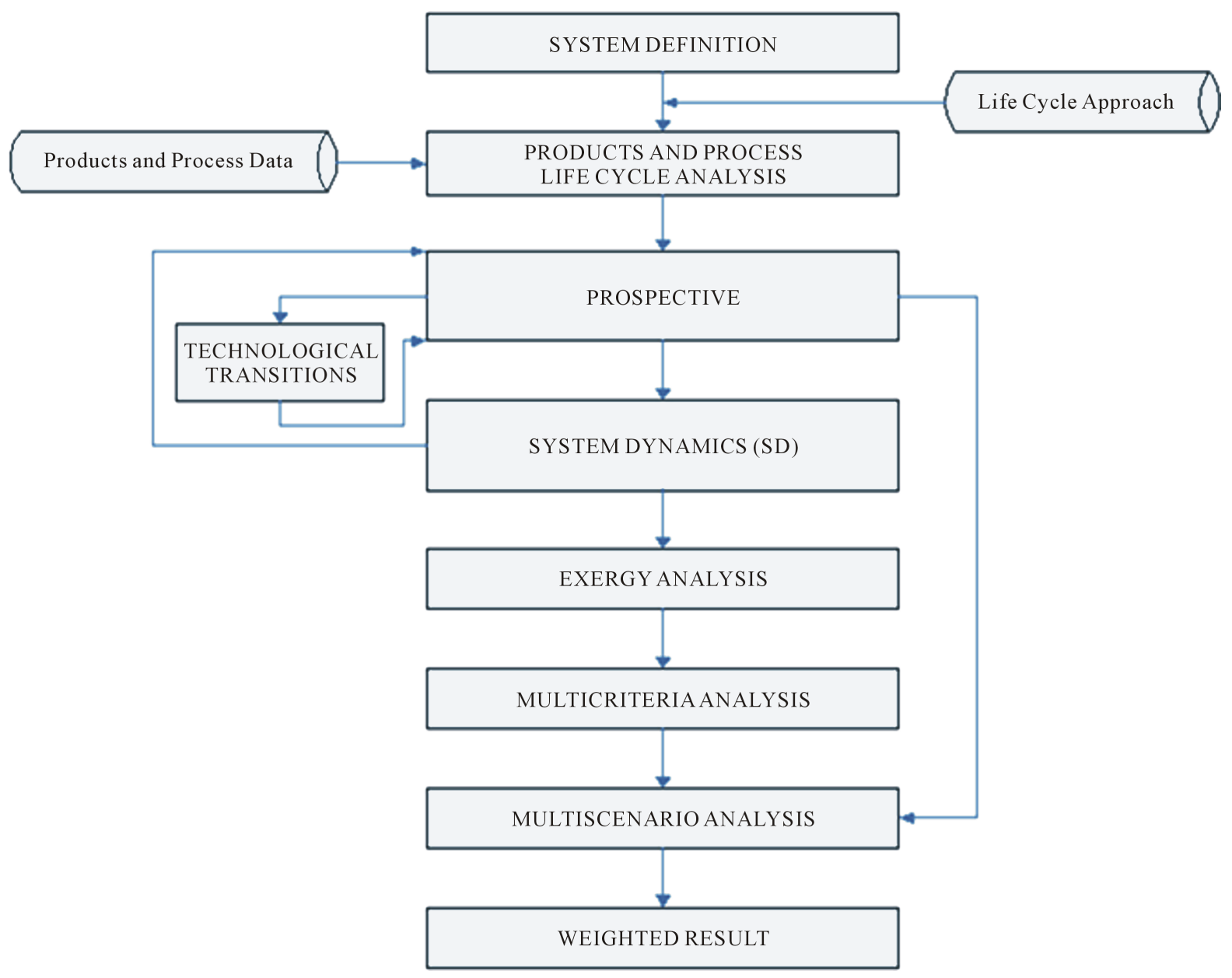

Figure 1. General description of methodology with system dynamics incorporation.

2) Energy consumption ( $\mathrm{MJ} / \mathrm{fu})$ to be interpreted also as the measure of natural resources.

3) GHG emissions (Ton. $\mathrm{CO}_{2 \mathrm{eq}}$ ).

4) Profit (\$/fu).

The alternatives studied are divided into two groups: bottles made from primary materials (virgin) and secondary materials (recycled) for each of the three types of packaging materials considered.

Figure 2 shows the resulting multicriteria ranking that has been analyzed with Visual PROMETHEE.

\section{Present Research}

The present research, focus on both: the impact of PET production via renewable resources to the PET life cycle [12], and the growth of recycled PET on its market. This market presents a strong material recovery rate and an increasing proportion of this material reincorporates to bottle production [13].

Within the system there are a lot of relationships that influence the variables already described. Udo de Hæs [14] emphasizes that attempt to take into account the dynamic effects of all processes involved in the life cycle, makes modeling work very complex and data requirements very extensive. Therefore modeling a small amount of key variables of the system is suggested as better solution.

The present study is an example of the approach mentioned above, where the model is built using first, the influence relationship between the key variables through structural analyses [15]. The model incorporates three dynamic processes, the first corresponds to PET production via hydrocarbons; the second, to the PET production via renewable resources, and the third, material recycling from PET waste deposition [16] [17].

The projection horizon is a long term one, considering 50 years. 


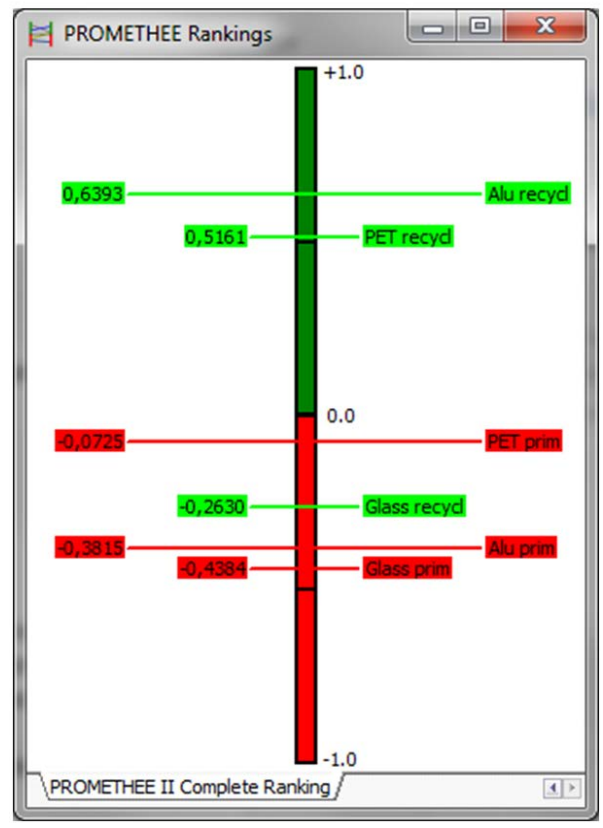

Figure 2. PROMETHEE ranking.

The data was obtained from NAPCOR, National Association for PET Container Resources. See reference [13].

The model assumes that:

1) We will study the influence of the rate of recycled material for bottles production, Equation (1), on the consumption annual growth rate for PET bottles, Equation (2), are function of the simulation time, Equation (3), according to NAPCOR's postconsumer PET reports data.

2) The presence of delays in the system due to renewable sources and recovery technologies.

$$
\begin{gathered}
\text { BUR }=0.049442 x^{0.541451} \\
\text { AGR }=\frac{0.17972}{x^{0.508789}} \\
x=\text { time }+ \text { TIMESTEP }
\end{gathered}
$$

where time corresponds to continuous standard time and TIMESTEP corresponds to integration method time step model selected, avoiding indetermination problems.

Figure 3 displays consumption annual growth rate behavior. It is clearly an initial boom on PET bottles consumption growth. Nevertheless, this growth reduced, mainly due to optimization of bottles design, recovery and recycled materials. On the other hand, PET bottle utilization rate, shows constant growth consumption due to increasingly interest and benefits on recycled and reformed material and the technologies involved.

To perform the calculations, a stock-and-flow model was built using VENSIM PLE ${ }^{\circledR}$ (version 5.11A) modeling software. Model structure is presented in Figure 4.

We should consider that material recovery feedback loop is turn off, then defining "recovery efficiency $=0$ ". Then, if recycling loop is active, "recovery efficiency" is considered $30.0 \%$.

On the other hand virgin material production process from renewable sources is subject to the definition of participation percentage or desired objective, into total virgin material production, allows disabling this process, if other scenario is required. In this study the renewable resources participation is $10 \%$.

The application to the present research which focus on the impact of PET production via renewable resources on the PET life cycle and the growth of recycled PET on its market. This market presents a strong material recovery rate and an increasing proportion of this material reincorporates to bottle production. Then the results and its application are based on Figure 4, stock and flow model. 


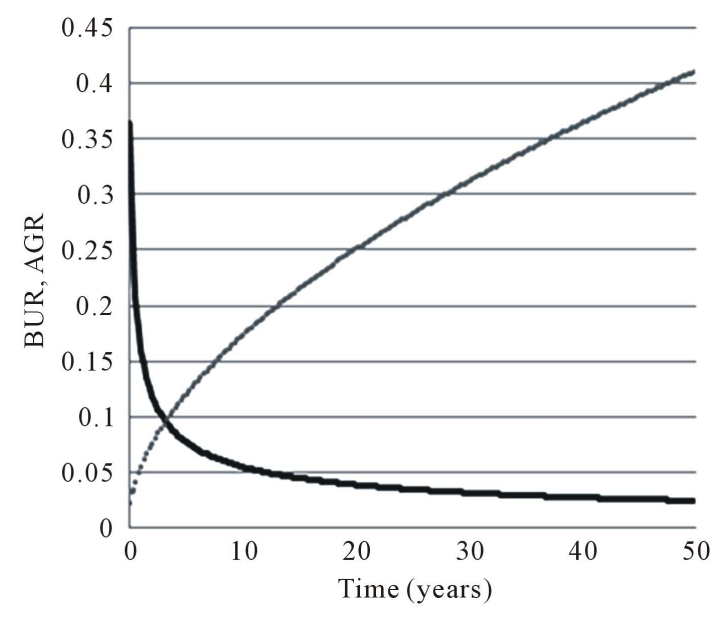

Figure 3. Annual growth rate and bottle utilization rate functions.

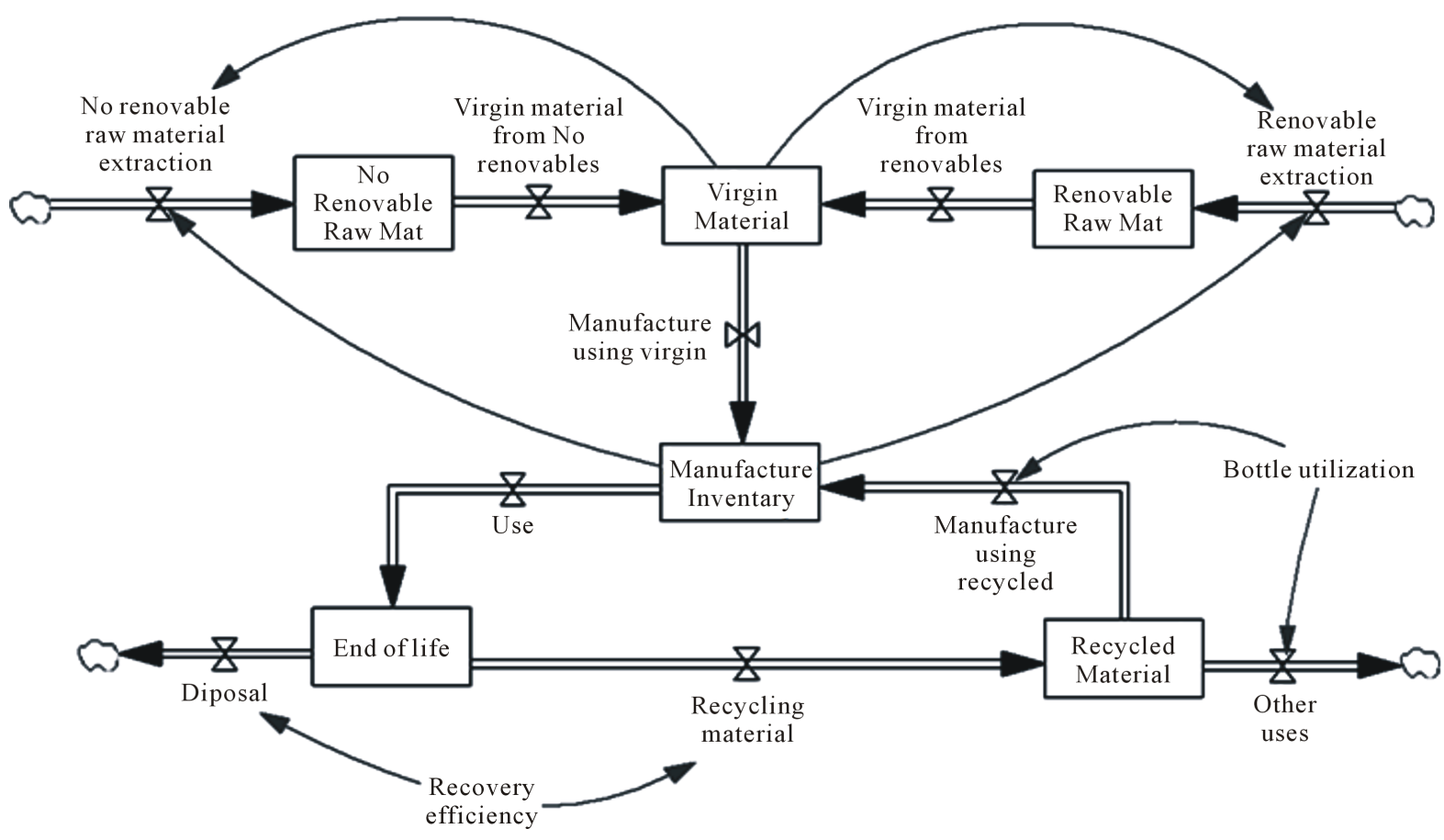

Figure 4. Simplified hypothetical stock-and-flow model showing feedback, delays structures and associated variables.

\section{Results}

A prospective study i.e. System Dynamics for Polyethylene Terephthalate as bottles has been performed, focused on petrochemical origin polymers and biopolymers with a horizon of 50 years.

The raw materials of petrochemical origin will go continue because oil and natural gas undergo major changes as depletion or replacement of its uses. Therefore, in this study we will always use petrochemical PET in some proportion according to model.

Biopolymers manufacturing technology and marketing will grow according with three scenarios, representing policies and/or action application strategies visualizing a petrochemical resources decline at year 30 of the planning horizon. These scenarios are described in Figure 7, Figure 8 and Figure 9. To establish those three scenarios, it was necessary to perform a sensitivity analysis of the following variables required by the model in the mass balance: 
1) Production of petrochemical inputs for PET: ethylene glycol and p-xylene.

2) PET production from renewable inputs, e.g. biomass.

3) The added output by recycling bottles whose production can be any of the previous two sources.

4) The production of recycled PET, whose consumption is dedicated to other uses different of packaging.

5) The PET not recovered and therefore moved to deposition assuming that these quantities will serve to generate electricity.

Figure 5 show the information fed into the model to perform sensitivity analysis, into the modified parameters were:

- Ef reco.-Presents the greatest impact on material flows as it depends on the availability of the material collection for recycling and therefore the replacement of virgin material.

- O renov inic.-Strong influence on the proportions of materials of petrochemical origin vs. the renewable origin.

- T assimilation technology._A minor delay in implementing technological contribution is more significant; however, the full impact remains relatively low due to the limitations of input sources.

- T recol.-Shorter time for recollection of material for recycling, more deposition is mitigated, promoting the amount of recycled material then impacting the production of virgin material.

- Ret bene.-To obtain different benefits as economic, political, social or other in less time (delay reduction), promotes the implementation of policies for recycling in the previous five years.

Figure 6 describes the results of the behavior in time of different PET flows accordingly to multi-parameter evaluation, where "Virgin Materials From No Renewables" and "Virgin Materials From Renewables" are new PET production flows respectively via petrochemical and bio-resources; "Other Uses" corresponds to recycled PET that is used in low performance applications like textile and scrub brushes; and, "Disposal" is the PET flow that ends in landfills. Blue, green, gray and yellow stripes are probability boundaries of PET flow in the proposed range of 50 years, where random uniform distributions are applied to model parameters evaluation. For example, the area between green stripes, which includes yellow and green stripes, represents $75 \%$ of possible PET flow variable profiles in the planning horizon. "Current" corresponds to the results associated to the initial values of the parameters above mentioned.

In Figure 7, the growth rate at which renewable technology is available to integrate the supply of the polymer in the medium term is shown as a red line. This technology would be ready to use 10 years before the possible decline of petrochemical-based polymers. In such a manner that when petrochemical input is declining, the total supply would be $50 \%$ for each raw material source.

The supply intersection among petrochemicals and biopolymers will have as a consequence, policies and/or actions that will break the intersection in favor of biopolymers, will require 30 years to complete the planning horizon of 50 years, achieving then, a contribution of $80 \%$ of virgin biomaterial to total PET production. The remaining $20 \%$ will be petrochemical material.

In the case of PET bottles in this first scenario, the total offer consists of virgin and recycled material. For example, in the year 50 the total supply will be 290,000 tons of PET bottles; 259,000 will correspond to virgin

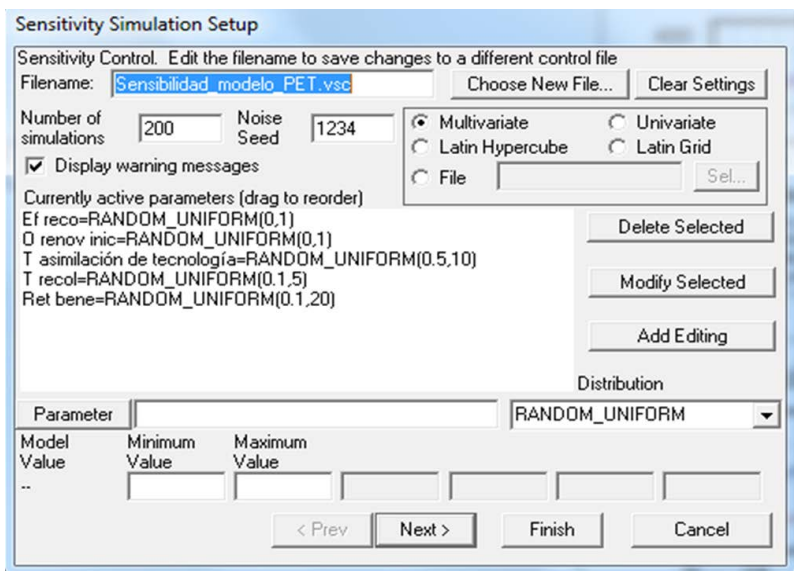

Figure 5. Sensitivity simulation parameters setup. 

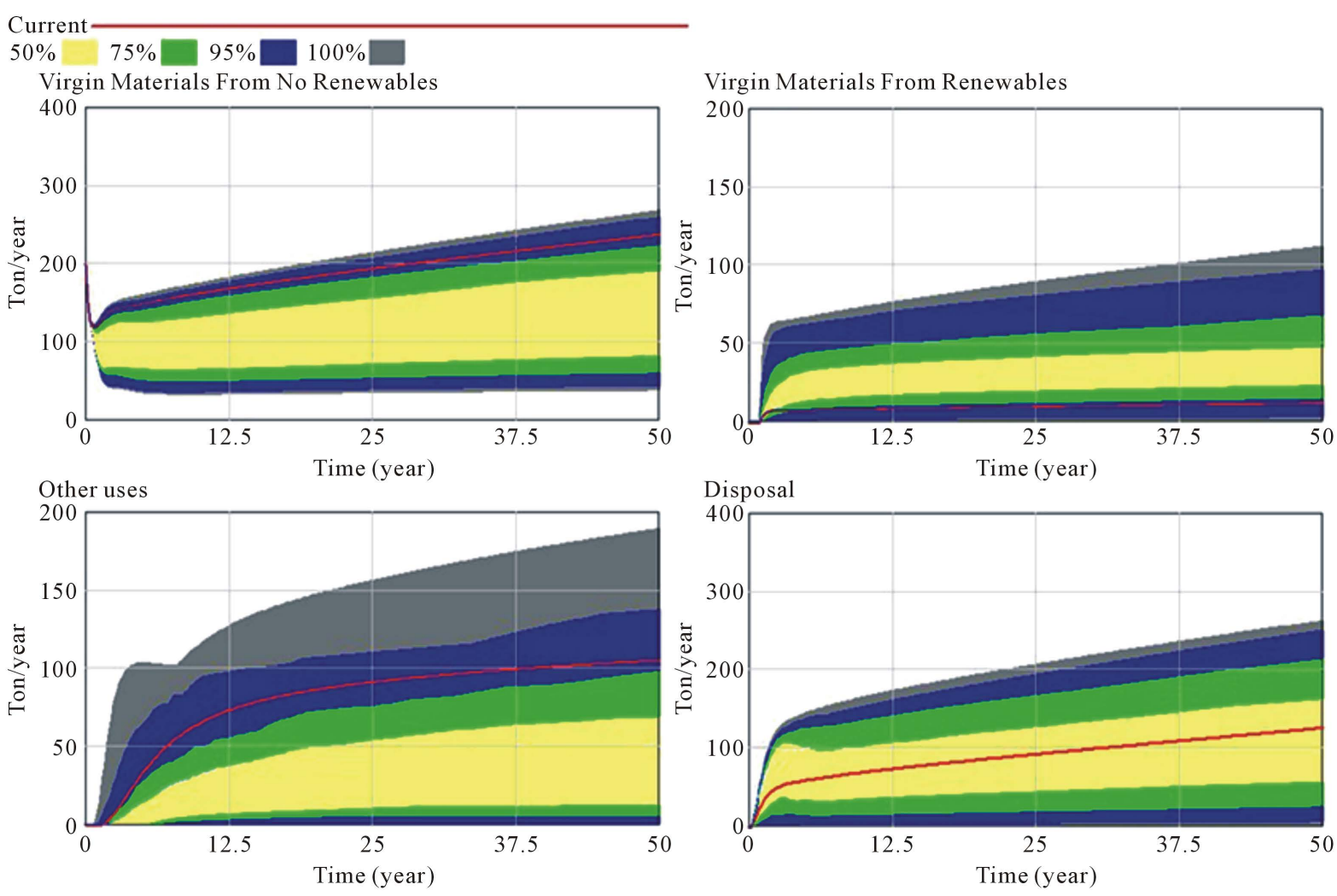

Figure 6. Sensitivity graphs for different model flows.

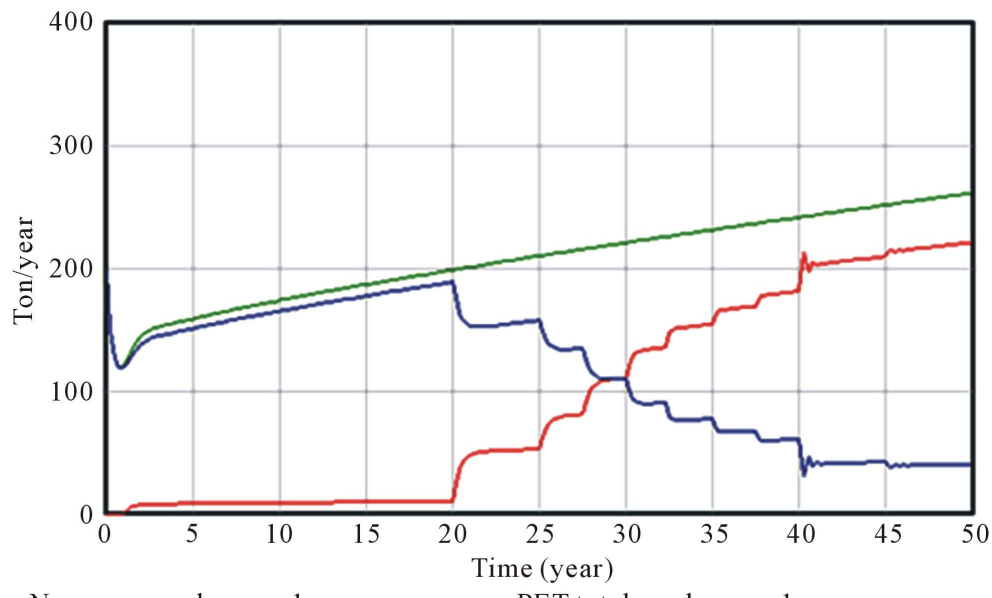

No renov prod: game 1

PET total prod: game 1

Renovable prod: game 1

Figure 7. Scenario 1, technology available for implementation 10 years before petrochemicals decline.

material (89.3\%), while recycled material will be 10.7\%, (33,900 tons).

It should be emphasized that these calculations started from the assumptions that were made at the beginning of the study.

In Figure 8, the rate at which technology will be available to integrate the PET supply in a medium-term will be possible at the time of the declining of the petrochemical-based polymer, (30 years) so that when declining arrives, the ratio of the integration of the supply of virgin material will be $94.9 \%$ petrochemical source, and thus only $5.1 \%$ bio material. 
The gap between virgin petrochemical and biomaterials, do not intersect at the end of the Planning Horizon. Nevertheless, the implementation of policies and/or actions that support the implementation of biopolymers will be required. In year 50, that is, 20 years after the technology adjustments, a contribution of these materials will be achieved to $34.9 \%$. So the petrochemical source will be $65.1 \%$.

Accordingly to second scenario, the total offer consists of virgin and recycled material; for the 50th year total supply would be 290,000 tons of PET bottles, of which 259,000 are virgin material. In the third scenario, Figure 9, the rate at which the technology for biopolymers, will be available 5 years after PH starts. The possible decline (year 30) of petrochemical origin is maintained so that the ratio of the integration of petrochemical virgin material supply will be $70 \%$ and therefore, $30 \%$ of bio origin.

The gap between petrochemical and bio virgin production intersects at PH 50th year. Therefore, implementation of policy actions that support bio polymer technologies will be needed. In the year 50, 20 years after the start of encouraging policies, a contribution of almost $50 \%$ virgin material production, will be achieved.

PET bottles, for the scenario number three, the total offer consists of virgin and recycled material; for the 50th year the total supply would be 290,000 tons of PET bottles, of which the proportions of virgin and recycled material remain the same.

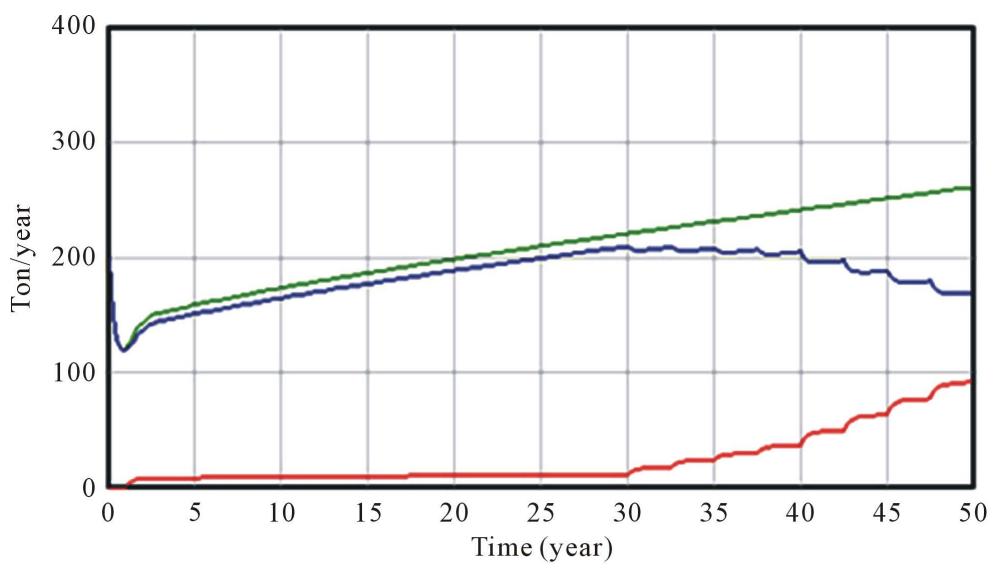

No renov prod: game 2

Renovable prod: game 2

PET total prod: game 2

Figure 8. Scenario 2, technology available for implementation considering petrochemicals decline.

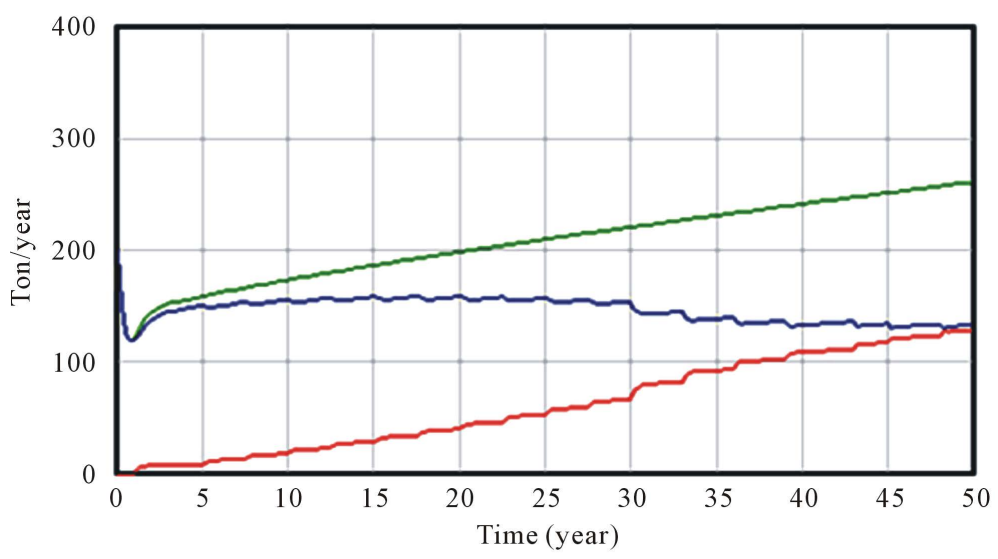

No renov prod: game 3

Renovable prod: game 3

PET total prod: game 3

Figure 9. Scenario 3, gradual technology implementation. 


\section{Conclusions}

This paper has presented a life-cycle analysis for Polyethylene Terephthalate as beverage packaging under system dynamics approach, taking into account production via renewable resources, as a contribution to decision making aid methodology.

Results show the usefulness of the system dynamics to display the behavior of the life cycle in time for plastic materials, in particular PET bottle. Including the life cycle management of the production of PET from renewable sources, significantly impacts of the total production of material, attributed to technology assimilation delay and therefore, the contribution to the total production.

The replacement with renewable materials has a limit. This limit is set by process technological efficiency and by required time to obtain a unit of virgin material. Then, the share of non-renewable sources to obtain PET will be maintained at low level, while development and optimization of technologies to use of renewable sources will continue.

Software tools, "sensitivity testing" and "gamming”, prove to be useful to generate scenarios under different premises of policies and actions, joining to the model parameters needed, so that prospective scenario analysis is affordable.

Bottle grade Polyethylene Terephthalate yield, via gas and oil technologies, can be reduced but not excluded from chain production, through generation and implementation of appropriate policies encouraging research and development of new PET synthesis technologies, via renewable and non-renewable resources, as well as those for chemical recycling of waste PET bottle resin.

The policies above mentioned, should take into account beverage industry growth prospective, so that production goal via renewable technology can be considered at the first stage; lately this goal can be reviewed and adjusted, according to new or evolving preferences, policies and resources availability.

Petrochemical polymers declining should be a major contributor to encourage biopolymers and recycling policies to supply PET bottle consumption in the planning horizon.

Improvement of system efficiency is strongly correlated to different fields of knowledge as biotechnology, genetics, process engineering and bio refining.

PET recycling, bottle to make bottles, has been constantly increasing, especially by environmental policies adopted by different corporations leading to a list of successes. An example is the 50,000 ton/year PETStar recycling plant start up in 2014, as it can be observed on the NAPCOR reports.

Increasing PET waste recovery efficiency and optimization of processes to improve added value to recycled PET resin, have an important effect in total production of bottles. As recycling sector continues to consolidate, maximizing recovery efficiency and adding value to PET recovered for high performance applications can minimize virgin PET requirements.

Collection activity is primary a logistics problem to guarantee supply for recycle plants.

Some of the conclusions herein obtained were not taken of this paper, but from the whole research. More research is in course about the model behavior under other premises, considerations and preferences, as well as to any other material, looking for the possibility to make the model a generalized one.

\section{Acknowledgements}

Financial support from Consejo Nacional de Ciencia y Tecnología (CONACYT, México) (Ph.D. scholarship to P. A. A.-J.) is gratefully acknowledged.

\section{References}

[1] Forrester, J.W. (1995) Couterintuitive Behavior of Social Systems. Technology Review, 73, 52-68.

[2] Sandén, B.A. and Karlström, M. (2007) Positive and Negative Feedback in Consequential Life-Cycle Assessment. Journal of Cleaner Production, 15, 1469-1481. http://dx.doi.org/10.1016/j.jclepro.2006.03.005

[3] Changsirivathanathamrong, A., Moore, S. and Linard, K. (2007) Integrating Systems Dynamics with Life Cycle Assessment: A Framework for Improved Policy Formulation and Analysis. Modelling and Simulation Society of Australia and New Zealand (MSSANZ).

[4] Stasinopoulos, P., Compston, P., Newel, B. and Jones, H.M. (2012) A System Dynamics Approach in LCA to Account for Temporal Effects a Consequential Energy LCI of Car Body-in-Whites. International Journal of Life Cycle Assessment, 17, 199-207. http://dx.doi.org/10.1007/s11367-011-0344-0 
[5] Dewulf, J. and Van Langenhove, H. (2004) Thermodynamic Optimization of the Life Cycle of Plastics by Exergy Analysis. International Journal of Energy Research, 28, 969-976. http://dx.doi.org/10.1002/er.1007

[6] Patel, M., Bastioli, C., Marini, L. and Würdinger, E. (2005) Life-Cycle Assessment of Bio-Based Polymers and Natural Fiber Composites. Biopolymers Online. http://dx.doi.org/10.1002/3527600035.bpola014

[7] Pilz, H., Brandt, B. and Fehringer, R. (2010) The Impact of Plastics on Life Cycle Energy Consumption and Greenhouse Gas Emissions in Europe. Denkstatt Gmbh.

[8] Harmsen, P. and Hackmann, M. (2013) Green Building Blocks for Biobased Plastics: Biobased Processes and Market Development. Wageningen UR Food \& Biobased Research.

[9] Escobar, C., García, C. and Mareschal, B. (2010) Petrochemical Industry: Assessment and Planning Using Multicriteria Decision Aid Methods. Technology and Investment, 1, 118-134. http://dx.doi.org/10.4236/ti.2010.12015

[10] Brans, J.P., Macharis, C., Kunsch, P.L., Chevalier, A. and Schwaninger, M. (1998) Combining Multicriteria Decision Aid and System Dynamics for the Control of Socio-Economic Processes. An Iterative Real-Time Procedure. European Journal of Operational Research, 109, 428-441. http://dx.doi.org/10.1016/S0377-2217(98)00068-X

[11] Mejía, L., Toledo, C. and Rayle, B. (2012) Decision Making in Sustainable Development: Some Methods to Evaluate Energy and Nonrenewable Resources Waste When Using Some Plastics. American Journal of Operations Research, 2, 399-407. http://dx.doi.org/10.4236/ajor.2012.23048

[12] De Jong, E., Higson, A., Walsh, P. and Wellisch, M. (2012) Bio-Based Chemicals: Value Added Products from Biorefineries. IEA Bioenergy-Task 42 Biorefinery.

[13] National Association for PET Container Resources, NAPCOR (1999-2013) Reports on Postconsumer PET Container Recycling Activity. Florence, KY, USA.

[14] Udo de Hæs, H.A., Heijungs, R., Suh, S. and Huppes, G. (2004) Three Strategies to Overcome the Limitations of LifeCycle Assessment. Journal of Industrial Ecology, 8, 19-32. http://dx.doi.org/10.1162/1088198042442351

[15] Quintero, D. and López, S. (2010) Análisis estructural: Un apoyo para el modelado con dinámica de sistemas. Revista Avances en Sistemas e Informática, 7, 153-161.

[16] Karayaniddis, G. and Achilias, D. (2007) Chemical Recycling of Poly(Ethylene Terephthalate). Macromolecular Materials and Engineering, 292, 128-146. http://dx.doi.org/10.1002/mame.200600341

[17] Dimonie, D., Socoteanu, R., Pop, S., Fierascu, I., Fierascu, R., Petrea, C., Zaharia, C. and Petrache, M. (2012) Overview on Mechanical Recycling by Chain Extension of POSTC-PET Bottles, Material Recycling — Trends and Perspectives.

http://www.intechopen.com/books/material-recycling-trends-and-perspectives/overview-on-mechanical-recycling-by-c hain-extension-of-postc-pet-bottles 